\title{
Surgical management of continuous and mixed type of OPLL in cervical spine: Experience in tertiary level hospital.
}

Md. Kamrul Ahsan ${ }^{1, *}$, Shahidul Islam Khan², Sachindra Raj Joshi ${ }^{3}$, Ravish Pandey ${ }^{3}$, Abu Rifat Md Mofazzal ${ }^{3}$, Abdullah AL Mahaj Chowdhury ${ }^{3}$, Nazmin Ahmed ${ }^{4}$

${ }^{1}$ Professor of Spinal Surgery, Department of Orthopaedic Surgery, Bangabandhu Sheikh Mujib Medical University (BSMMU), Shahbag, Dhaka

${ }^{2}$ Medical Officer, MS (Orthopaedic Surgery), Dept of Orthopaedic Surgery, BSMMU, Dhaka

${ }^{3}$ Resident, Department of Orthopaedic Surgery, BSMMU

${ }^{4}$ Registrar Department of Neurosurgery, BIRDEM, Dhaka, Bangladesh

*Corresponding author: Kamrul Ahsan, Professor of Spinal Surgery, Department of Orthopaedic Surgery, Bangabandhu Sheikh Mujib Medical University (BSMMU), Shahbag, Dhaka

Received date: 19 November, $2021 \mid$

Accepted date: 29 November, $2021 \mid$

Published date: 1 December, 2021

Citation: Ahsan K, Khan SI, Joshi SR, Pandey R, Mofazzal AR, et al. (2021). Surgical management of continuous and mixed type of OPLL in cervical spine: Experience in tertiary level hospital. J Orthop Pract 1(1). doi https://doi.org/10.54289/JOP2100104

Copyright: @ 2021 Ahsan K, Khan SI, Joshi SR, Pandey R, Mofazzal AR, et al. This is an open-access article distributed under the terms of the Creative Commons Attribution License, which permits unrestricted use, distribution, and reproduction in any medium, provided the original author and source are credited.

\section{Abstract}

Background: Ossification of the posterior longitudinal ligament (OPLL) is a chronically progressive disease of ectopic enchondral and membranous ossification of posterior longitudinal ligament (PLL). Controversy still persists over the superiority of various surgical approaches for cervical OPLL management.

Purpose: To see the efficacy of expansive laminoplasty for the management of continuous and mixed type of cervical OPLL retrospectively.

Methods: Records of 20 male and 8 female aged 36-72 years (mean, 56.64 years), who underwent surgical treatment posteriorly for continuous and mixed type OPLL by laminoplasty were obtained from the year 2004 - 2020. Clinical features along with imaging studies, which included X -ray/CT /MRI, were done for the diagnosis of OPLL. Multiple variables were studied, including demographics, surgical parameters, complications and functional outcomes.

Results: They were followed on an average of $59.86 \pm 20.95$ months (range, $24-108$ months). The average operative duration was $95 \pm 15.52 \mathrm{~min}$ (range: 70 - 140), and the intraoperative blood loss was 199.29 $\pm 33.55 \mathrm{ml}$. The cervical curvature index reduced to $8.81 \pm 1.96$ from $11.00 \pm 2.49$ and the VAS score decreased from $4.25 \pm 0.75$ to $2.43 \pm 1.40$. mJOA score improved from $8.64 \pm 1.03$ to $13.96 \pm 1.26$ on the last follow-up after surgery $(\mathrm{p}<0.01$ ), with average recovery rate of $65.5 \%$.

Conclusions: The management for cervical myelopathy with multilevel stenosis due to continuous and mixed type of OPLL by Laminoplasty is safe and effective.

Keywords: Ossification of the posterior longitudinal ligament; laminoplasty; continuous and mixed type of OPLL.

Abbreviations: OPLL: Ossification of the posterior longitudinal ligament, PLL: posterior longitudinal ligament, LP: Cervical laminoplasty, LT: Laminectomy, LF: Ligamentum flavum, VAS: Visual Analog score, mJOA: Modified Japanese Orthopaedic Association score 


\section{Introduction}

OPLL is a chronically progressive disease of ectopic enchondral and membranous ossification of posterior longitudinal ligament (PLL), of unknown etiology [1]. Once also called 'Japanese disease', it's one of the key reasons of cervical myelopathy and /or radiculopathy. It was first described in 1960 by Tsukimato a Japanese scholar, where hypervascular fibrosis of PLL resulted in focal area of calcifications, periosteal cartilaginous proliferations and ossifications [2]. It progresses, annually at the rate of $0.67 \mathrm{~mm}$ in the antero-posterior and $4.1 \mathrm{~mm}$ longitudinal directions, and also frequently extends into dura [3]. The reported prevalence of OPLL in the Japanese is $2-3.5 \%$, China $0.2 \%$ - $1.8 \%$ and Korea $0.95 \%$, whereas in Europeans or North Americans it is less than $1 \%$ [4,5,6]. Although poorly understood, there is general agreement that pathogenesis of OPLL is multifactorial, representing a complex interaction of underlying genetic and environmental factors [7]. Recent genetic analysis suggests the involvement of certain genes, such BMP4, BMP9, COL6A1, COL11A2 and NPPS in the origin of OPLL. The fibroblasts derived from OPLL patients exhibits osteoblast - like properties and PERK (a membrane protein kinase) is significantly upregulated in cells from these patients in contrast to those from non OPLL patients $[6,7,8]$. There are many classifications of OPLL but widely used is that of, Investigation Committee on OPLL of the Japanese Ministry of Health, Labour and Welfare. On the basis of lateral imaging, they are categorized into four types: Segmental, Continuous, mixed and focal [9]. Frequent progression to myelopathy has been observed in continuous and mixed types. Depending upon the type, the management of cervical OPLL has been described by various surgical approaches, but continues to be controversial. The classification and extent of OPLL, stenosis severity, cervical spine sagittal alignment and instability, previous surgery; and surgeons experience dictates the ideal surgical approach.

Cervical laminoplasty (LP) and laminectomy (LT) with or without fusion are the most commonly used procedures for addressing the multilevel OPLL which can decompress the cord either directly or indirectly but in laminoplasty, it enlarges the spinal canal with preserving the posterior structures and myelopathic progression is less, patient satisfaction is more along with lower rate of complications $[10,11]$. The main aim of this study was to evaluate the clinical outcomes of 28 patients with continuous and mixed type of cervical OPLL following expansive laminoplasty.

\section{Methods:}

From January 2004 to January 2020, total 38 OPLL patients underwent surgery in our tertiary level hospital which included 8 segmental, 2 circumscribed, 16 continuous and 12 mixed type of OPLL. Records of 20 men 8 women aged 3672 years (mean, $56.64 \pm 7.76$ years), who underwent surgical treatment posteriorly for continuous and mixed type OPLL by open door laminoplasty at C3-5 level $(n=10), C 3-6(n=12)$ and C4-6 $(n=6)$ were retrospectively reviewed. Other conditions associated with OPLL were diabetes mellitus $(\mathrm{n}=$ 16), diffuse idiopathic skeletal hyperostosis $(\mathrm{n}=4)$, ankylosing spondylitis $(\mathrm{n}=1)$, ossification of ligamentum flavum at D10-11, D11-12 ( $\mathrm{n}=5)$, obesity $(\mathrm{n}=3)$ and hypoparathyroidism $(n=2)$. Approval from the institutional research ethics committee was acquired and informed consents were obtained from all participating patients. Inclusion criteria were: (1) continuous and mixed type OPLL (2) involvement 3 or $>3$ level and (3) neutral to lordotic C2-7 alignment and (4) both K-line positive or negative OPLL patients. Excluded were:(1) segmental and focal type of OPLL (2) hill-shape ossification, (3) spinal canal stenosis > $60 \%$, (4) loss of cervical curvature and (5) instability. All patients had axial neck pain along with pain and muscle weakness in upper limb; and lower limb clinical features were that of upper motor neuron type (e.g., weakness, incoordination, clumsiness and spasticity). Diagnosis was made by X-ray, CT scan and MRI along with clinical features (Figure 1: A, B, C, D, F, G). X-ray cervical spine standard and dynamic (flexion and extension) views were done to see the dense ossification along the back of the vertebral bodies and instability especially on the lateral x-ray. CT scan of cervical spine along with screening film were done to see the extend and type of OPLL, identified any foraminal component or the degree of stenosis, ossification of ligamentum flavum or any evidence of diffuse idiopathic skeletal hyperostosis (DISH) as well as the double layer sign on axial bone window which is characteristic feature of dural 
ossification. The extent of spinal cord compression as well as any pathological changes in the spinal cord was assessed by Magnetic resonance imaging (MRI). The OPLL appears hypointense in MRI which gets enhanced after gadolinium injection. In case of pathological changes, T1 weighted shows hypointense and T2 weighted shows hyperintense signal changes in spinal cord.
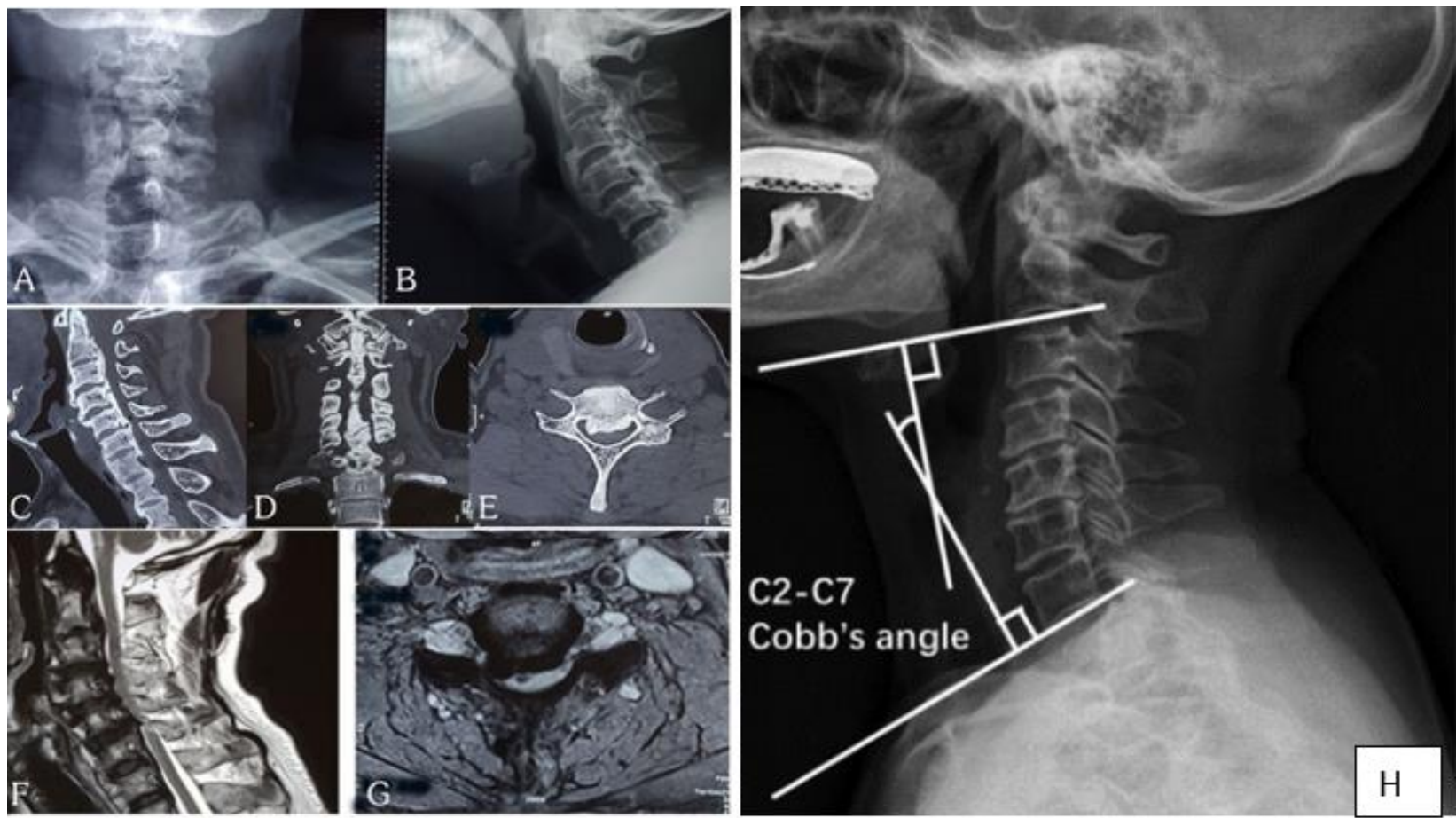

Figure 1. Preoperative plain X-ray A-P and lateral view (A, B), Sagittal, coronal and axial section CT scan (C, D, E) shows continuous type OPLL and (E, F) Sagittal and axial section T2 weighted MRI shows OPLL compressing the cord at C3 - 6 level with myelomalacic change at C 5/6 level and measurement of the C2 - C7 Cobb's angle (H). The C2 - C7 Cobb's angle is defined as the angle between two lines perpendicular to the lower endplates of $\mathrm{C} 2$ and $\mathrm{C} 7$.

After evaluation of medical records of all patients (28 patients), we documented all demographic parameters that included age, gender, body mass index (BMI), associated other condition, extend and type of OPLL; and surgical data which include operative duration, intraoperative blood loss, operative complications, duration of hospital stay, pre- and post-operative VAS for pain. Clinical features were evaluated pre- and postoperatively by Japanese Orthopaedic Association (JOA) score [12] (Table 1) and the recovery rate following surgery were measured by the formula as defined by Hirabayashi et al [13].

Postoperative score - preoperative score

(Recovery rate $(\%)=$ $\times 100)$.

Normal score (17) - preoperative score 
Table 1: Modified Japanese Orthopedic Association score for assessment of myelopathy ${ }^{12}$

\begin{tabular}{|c|c|c|c|c|c|c|c|}
\hline \multicolumn{2}{|r|}{ Upper extremity function } & \multicolumn{2}{|c|}{$\begin{array}{l}\text { Lower extremity } \\
\text { function }\end{array}$} & \multicolumn{2}{|c|}{ Sensations } & \multicolumn{2}{|c|}{ Bladder functions } \\
\hline \multirow[t]{2}{*}{0} & \multirow[b]{2}{*}{$\begin{array}{l}\text { - Unable to feed oneself with a } \\
\text { spoon or by using fingers } \\
\text { - Inability to hold a pen } \\
\text { - Total inability to carry out } \\
\text { finger hand function like } \\
\text { buttoning shirt/house, attaching } \\
\text { watch strap }\end{array}$} & \multirow[t]{2}{*}{0} & \multirow{2}{*}{$\begin{array}{l}\text { Unable to walk by any } \\
\text { means }\end{array}$} & \multicolumn{2}{|r|}{ Upper limp } & \multirow[t]{2}{*}{0} & \multirow[t]{2}{*}{ Retention } \\
\hline & & & & 1 & $\begin{array}{l}\text { Apparent sensory loss } \\
\text { Minimal sensory loss } \\
\text { Normal }\end{array}$ & & \\
\hline \multirow[t]{2}{*}{1} & \multirow{2}{*}{$\begin{array}{l}\text { - Able to feed oneself with a } \\
\text { spoon but not with hands } \\
\text {-Able to hold pen but unable to } \\
\text { write }\end{array}$} & \multirow[t]{2}{*}{1} & \multirow{2}{*}{$\begin{array}{l}\text { Unable to walk } \\
\text { without a cane or } \\
\text { other support on the } \\
\text { level. }\end{array}$} & \multicolumn{2}{|r|}{ Lower limp } & \multirow[t]{2}{*}{1} & \multirow{2}{*}{$\begin{array}{l}\text { Severe disturbance } \\
\text {-Inadequate evacuation the } \\
\text { bladder } \\
\text { - straining } \\
\text { •dribbling of urine }\end{array}$} \\
\hline & & & & 0 & $\begin{array}{l}\text { Apparent sensory loss } \\
\text { Minimal sensory loss } \\
\text { Normal }\end{array}$ & & \\
\hline \multirow[t]{2}{*}{2} & \multirow[b]{2}{*}{$\begin{array}{l}\text { - Clumsiness while eating food } \\
\text { with hands } \\
\text { - Able to write, but with great } \\
\text { difficulty } \\
\text { - Difficulty in buttoning/ } \\
\text { Unbuttoning shirt/ blouse, } \\
\text { attaching watch strap }\end{array}$} & \multirow[t]{2}{*}{2} & \multirow{2}{*}{$\begin{array}{l}\text { Able to walk } \\
\text { independently on the } \\
\text { level but needs } \\
\text { support on stair }\end{array}$} & \multicolumn{2}{|r|}{ Trunk } & \multirow[t]{2}{*}{2} & \multirow{2}{*}{$\begin{array}{l}\text { Mild disturbance } \\
\bullet \text { Hesitancy } \bullet \text { Frequency }\end{array}$} \\
\hline & & & & 0 & $\begin{array}{l}\text { Apparent sensory loss } \\
\text { Minimal sensory loss } \\
\text { Normal }\end{array}$ & & \\
\hline 3 & $\begin{array}{l}\text { - Change in handwriting due to } \\
\text { clumsiness } \\
\text {-Slightly clumsy in buttoning } \\
\text { shirt/blouse, attaching watch strap }\end{array}$ & 3 & $\begin{array}{l}\text { Slightly clumsy in } \\
\text { walking }\end{array}$ & & & 3 & Normal \\
\hline 4 & Normal & 4 & Normal & & & & \\
\hline
\end{tabular}

Total score $=17$

Recovery rates was divided into 4 grade scale depending on improvements, i.e., excellent $\geq 90 \%$, good 75 - 89\%, fair 50 $74 \%$, and poor $\leq 49 \%[14]$.

To assess the cervical alignment, Cobb's angle was calculated by means of cervical spine $\mathrm{X}$-ray from C2 - C7, in lateral view with neck at neutral position. It was assessed preoperatively and at $3^{\text {rd }}, 6^{\text {th }}$ month and at final follow up as well (Figure 1: H; 2: A, B). The Cobb's angle of $<0^{\circ}$ is specified as cervical Kyphosis. The change of cervical alignment was measured by calculating the difference between the preoperative and postoperative Cobb's angle. The change in cervical alignment of $>0^{\circ}$ was considered as loss of cervical lordosis (LCL). Occupancy ratio can be calculated by dividing a (Antero-posterior diameter of OPLL) by b (spinal canal AP diameter) and multiplying by 100 (Figure 3: A, B). All the data were compiled and sorted properly. The data were analyzed statistically by using SPSS (version-25, Armonk, NY, IBM Corp). The differences between clinical parameters were compared by Pair student's $t$ test and $p$ value $<0.05$ was set up as level of significance. 


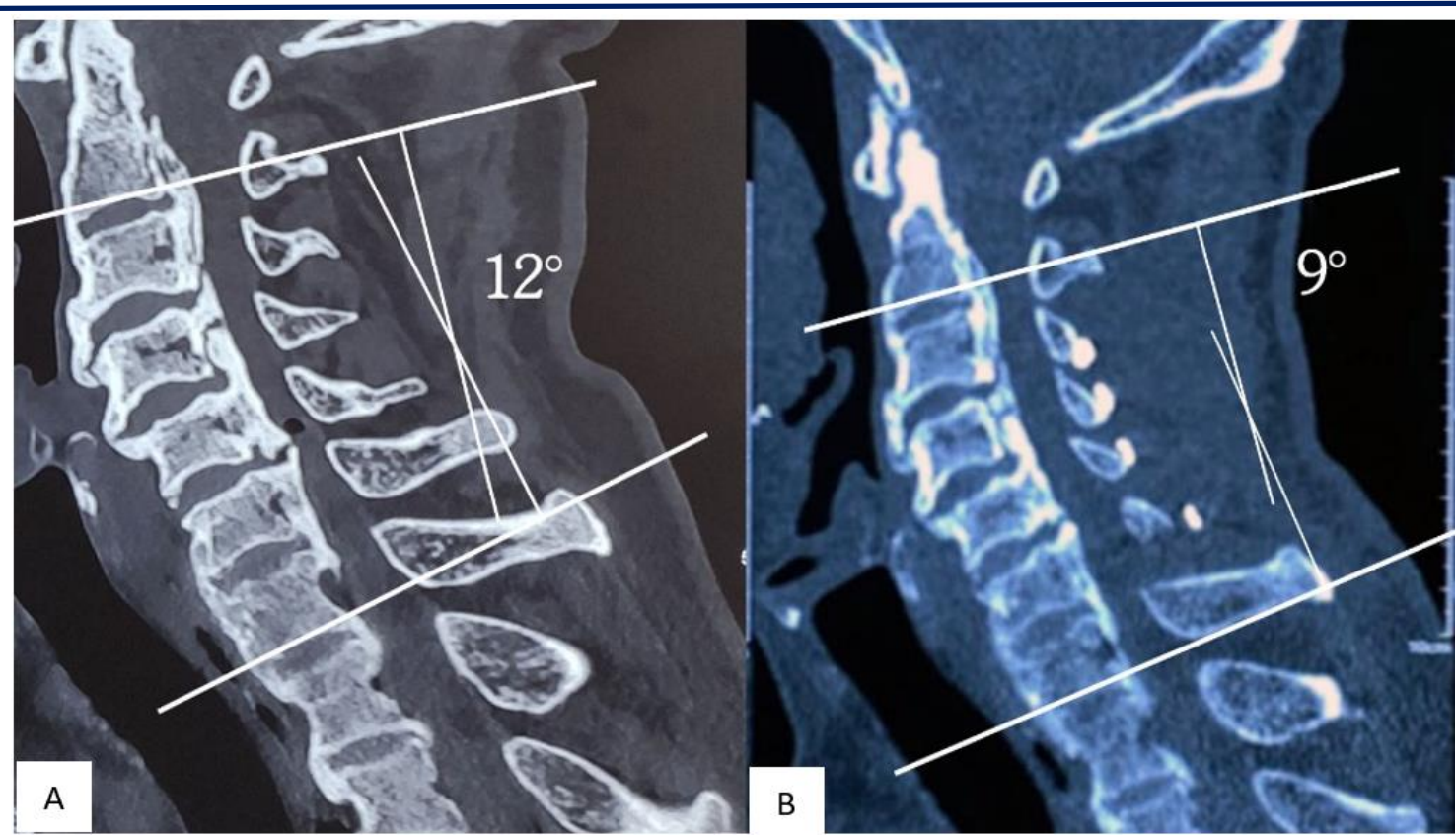

Figure 2: (A) shows preoperative cobb's angle $12^{0}$ and (B) postoperative cobb's angle $9^{0}$ after 12 -months.

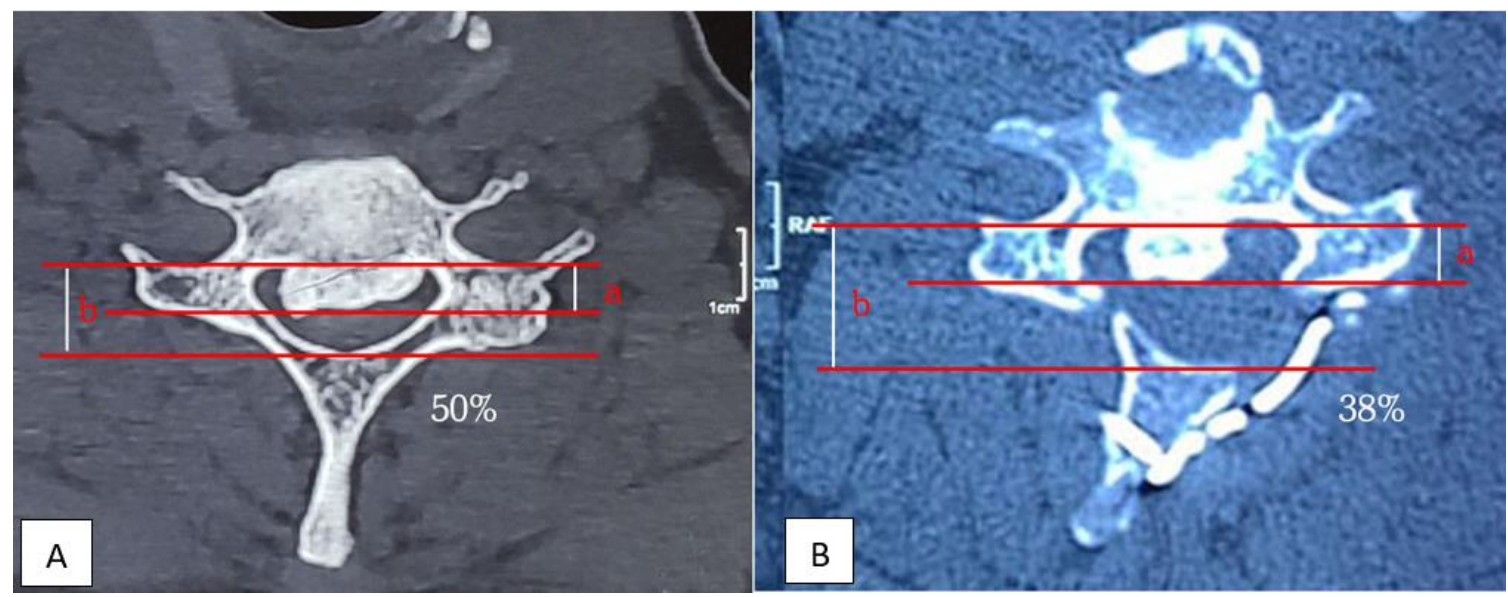

Figure 3: (A) shows preoperative occupancy ratio 50\% and (B) postoperative occupancy ratio 38\% after 12-months.

\section{Surgical procedure}

After obtaining intravenous and arterial access line, all patients underwent general anaesthesia with intubation without cervical extension (either by glidescope or video laryngoscope). After catheterization, the patient is positioned prone with knees flexed so that the patient doesn't migrate caudally. The cervical spine is roughly oriented parallel to the floor by keeping the bed in reverse Trendelenburg position, also the neck placed in a neutral or slightly flexed alignment by Mayfield head holder. The shoulders are taped and the arms are tucked at the sides of the patient with thumbs pointed towards the floor. The knees, legs, and abdomen are well padded. Then painting and draping of head and neck region are done in standard fashion. Then the midline incisional area is infiltrated with a long-acting local anesthetic supplemented with epinephrine which minimizes blood loss and postoperative pain. A midline longitudinal incision from $\mathrm{C} 2$ to C7 spinous process was made. The electrocautery is then used to incise the ligamentum nuchae, followed by subperiosteal dissection and retraction of paracervical musculature. During surgery, retractors are released periodically to allow adequate perfusion, avoiding necrosis and denervation of the muscles. As semispinalis cervicis muscle has vital role in preserving the alignment of the cervical spine, all precaution were taken After the laminae of C3 - 6 were exposed on both sides, opening was made on the side where the patients had more symptoms. An opening is made on the lateral margin of the lamina in one side (open side); whereas in the hinge side, 
gutter was made by removing only the dorsal cortex and cancellous bone. The laminoplasty is then sequentially opened by exerting a dorsolateral pressure on the lamina, lifting it away from the canal and simultaneously, creating segmental greenstick fractures. During this maneuver, the ligamentum flavum (LF) will come under tension and needs to be released with kerrison rongeur. Once all the lamina is elevated on the open side, fixation is applied in the form of titanium miniplates (double-bended 10 or $12 \mathrm{~mm}$ plate) and screws (7 or $8 \mathrm{~mm}$ in length, 1.8 or $2 \mathrm{~mm}$ diameter) (Figure 4

A, B, C, D; 5 a, A, B). This is classic Hirabayashi expansive open door laminoplasty devised by the author in 1977
$[16,17]$. After the fixation of open side, if additional space was required; a dome-like resection was performed over the inferior and the superior one-third of the C2 \& C7 lamina, respectively; without damaging the muscle-ligamentous complex. We also performed foraminotomies where indicated. On the open side, we performed foraminotomies after laminoplasty and plate fixation, whereas, on the hinge side foraminotomies were performed prior to laminoplasty. Meticulous hemostasis was obtained followed by wound closure in layers with drain in situ. Post operatively, cervical collar was used to immobilize the neck for 3 - 4 weeks.

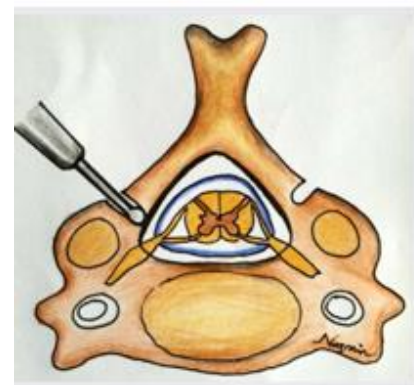

A

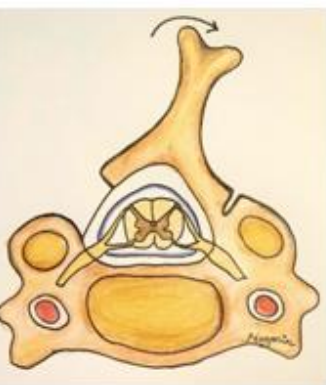

B

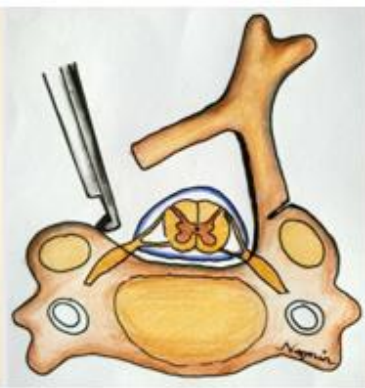

C

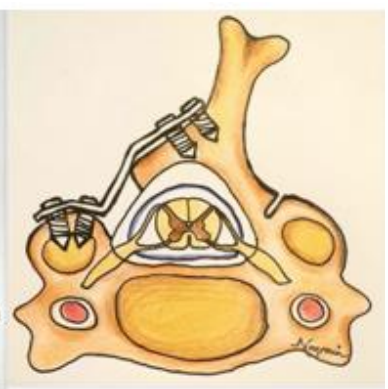

D

Figure 4: Schematic picture demonstrated the laminoplasty technique. (A) The opening is created at the lateral mass-laminar junction by angling the burr perpendicular to the lamina and the opposite side creating a hinge, leaving the ventral cortex intact; (B) greenstick fractures are created by placing dorso-lateral tension on the spinous process or cut edge of lamina;(C) the ligamentum flavum is put under tension and cut with a Kerrison rongeur. (D) Fixation is applied.

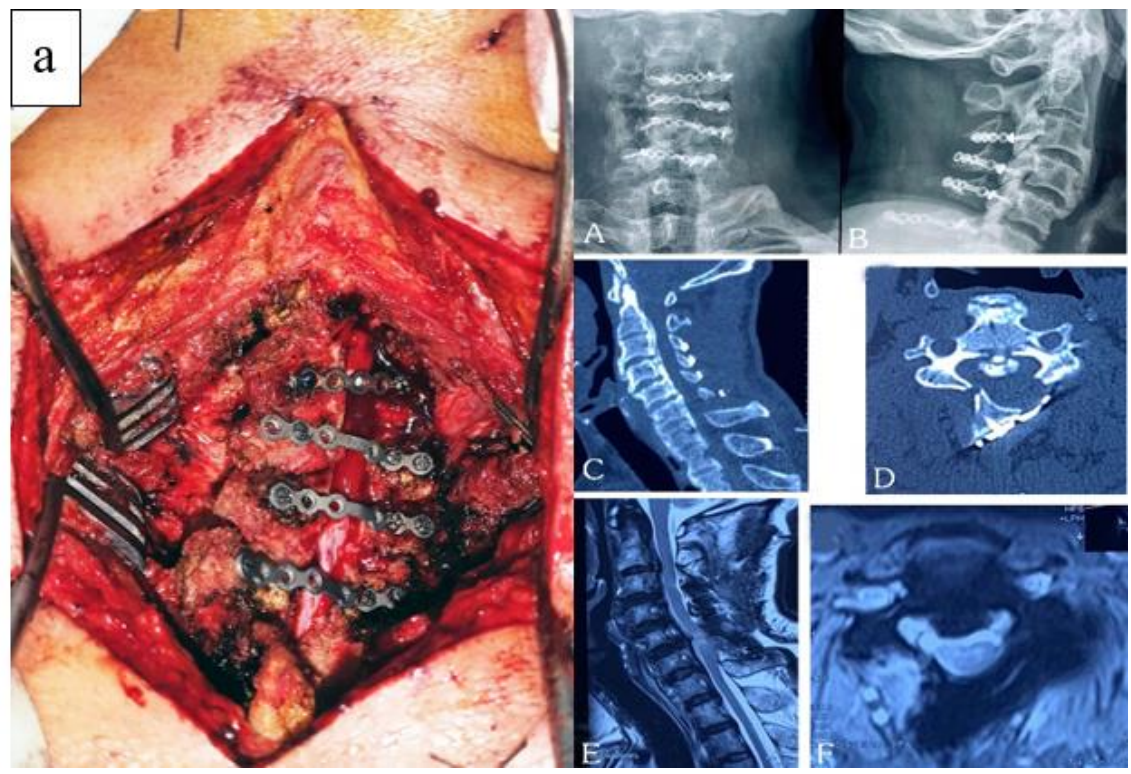

Figure 5: (a) per-operative picture of 58-year-old male patient showing fixation by reconstruction mini plate and screws, (A, B) post operative plain X-ray A-P and lateral view, (C, D) Sagittal and axial section CT scan and (E, F) T2 weighted Sagittal and axial section MRI shows adequate enlargement of canal at 12 months follow up. 


\section{Results:}

They were followed on an average of $59.86 \pm 20.95$ months (range, 24 -108 months). Preoperatively, 24 patients had lordotic and 4 patients had neutral sagittal alignment. Among 28 patients, 26 patients had $\mathrm{K}$ line (+) and 2 patients had $\mathrm{K}$ line $(-)$. The mean duration of suffering was $41.64 \pm 6.28$ months (range, 24-53 months). The average operative duration was $95 \pm 15.52 \mathrm{~min}$ (range: 70 - 140), and the blood loss was $199.29 \pm 33.55 \mathrm{ml}$ (range, $140-260 \mathrm{ml}$ ). The average duration of hospital stay was 4 days (range, 3 to 7 days). The mean $\mathrm{C} 2-\mathrm{C} 7 \mathrm{Cobb}$ 's angle was $9.43^{\circ} \pm 1.29^{\circ}$ (range, $7^{\circ}-14^{\circ}$ ) before surgery and after surgery the mean cobb's angle was reduced to $7.04^{\circ} \pm 1.32^{\circ}$ (range, $5^{\circ}-10^{\circ}$, p $<0.001$ ) with the mean of LCL of $2.39^{\circ}$ and $10.71 \%$ of patients (3 of 28) developed kyphosis postoperatively. The occupying ratio of OPLL was $47.57 \pm 5.64 \%$ (range, $40 \%$ $60 \%$ ) before surgery and after surgery occupying ratio was reduced to $35.64 \pm 5.76 \%$ (range, $30 \%-53 \%$, < 0.001 )

(Figure 3 A, B). The VAS score decreased from $4.25 \pm 0.75$ to $2.43 \pm 1.40$. mJOA score improved from preoperative 8.64

\pm 1.03 to $13.96 \pm 1.26$ on last follow-up, postoperatively ( $\mathrm{p}<$ 0.01 ); with average recovery rate of $65.5 \%$. (Table 2). Figure 5 (C, D, E, F) revealed adequate expansion of the canal as well as decreased occupying ratio. During operation, two patients $(7.1 \%)$ developed dural tear and 2 patients (7.1\%) developed hinge breakage and were managed accordingly. Post-operative paresthesia developed in 2 (7.1\%) patients after 1 month of follow up, who recovered within 3 months. Besides, two patients (7.1\%) developed transient C5 palsy, and presented with shoulder abduction weakness; they recovered within 6 months. Three patients (10.7\%) reported occasional axial neck pain. Full recovery of these patients was attained after 3 months of physical therapy. There were no wound infections or postoperative hemorrhage. Late neurological deterioration of cervical myelopathy was developed in 4 patients. Among them, two patients developed late deterioration at 3 years after operation and another 2 patients developed late deterioration at 8 and 9 years after surgery.

Table 2: Clinical outcome assessment by Modified Japanese Orthopedic Association score

\begin{tabular}{|c|c|c|c|}
\hline Criteria & Pre-operative & Post-operative & p value* $^{*}$ \\
\hline Upper extremity function & $1.61 \pm 0.50$ & $2.89 \pm 0.63$ & $<0.001$ \\
\hline Lower extremity function & $1.32 \pm 0.48$ & $3.07 \pm 0.38$ & $<0.001$ \\
\hline Upper limb sensation & $1.00 \pm 0.00$ & $1.61 \pm 0.50$ & $<0.001$ \\
\hline Lower Limb Sensation & $1.46 \pm 0.51$ & $1.93 \pm 0.26$ & $<0.001$ \\
\hline Trunk Sensation & $1.50 \pm 0.51$ & $1.89 \pm 0.32$ & $<0.001$ \\
\hline Bladder function & $1.75 \pm 0.52$ & $2.57 \pm 0.50$ & $<0.001$ \\
\hline Total JOA Score & $8.64 \pm 1.03$ & $13.96 \pm 1.26$ & \\
\hline Recovery rate & \multicolumn{2}{|c}{$64.65 \%$} & \\
\hline
\end{tabular}

* Paired $\mathrm{t}$ test performed.

\section{Discussion:}

OPLL is a multifactorial hyperostosis disorder of the PLL that can occur throughout the spine; however, a more commonly affected region is cervical vertebra, which is also one of the factors for cervical myelopathy. Hirabayashi et al. was first to introduce Laminoplasty [16]. Laminoplasty is an effective posterior decompression technique, which is popular among the spinal surgeons for the selected patients with cervical compressive myelopathy, and also have been established for cervical OPLL [17]. Laminoplasty results in direct and indirect decompression of the spinal cord, directly via an enlargement of spinal canal dimensions and removal of LF and indirectly by allowing the spinal cord to drift away from the anterior compressive lesion and also, it preserved the cervical motion. Patients with OPLL are either asymptomatic or may present with myelopathy or myeloradiculopathy. Though there is no effective conservative treatment, patients without myelopathic symptoms or with mild symptoms should be primarily managed nonoperatively. This also accounts for patients with confirmed irreversible neurological 
damage, those who can't tolerate surgery or refusing surgery; and also, in patients where neural functions weren't restored after surgical decompression. Surgical intervention is suggested for those with moderate to severe myelopathy and or myeloradiculopathy or in patients where conservative treatment fails. Both anterior and posterior approach can be used as surgical intervention for cervical OPLL. As the lesion in OPLL lies anteriorly, the anterior approach seems to be more feasible. However, this approach is technically demanding and has been linked with a higher rate of serious complications, such as massive intraoperative bleeding, neural injury, symptomatic CSF leakage, graft dislodgement, reconstruction failure and adjacent segment disease. On the other hand, the posterior approach is relatively easier, where the entire cervical spine can be decompressed but as the disease progresses, patients may develop late neurological deterioration. Though it is not suggested for prophylactic surgery in asymptomatic patient because of the risk of the surgery, however early surgical decompression is recommended in patients with apparent myelopathy or even mild myelopathy with severe spinal stenosis, as irreversible change in spinal cord may develop due to long-standing compression of the spinal cord [18]. The optimal approach is decided by patient's general conditions, number of OPLL lesions, type and shape of OPLL, sagittal alignment, severity of stenosis (SAC and occupying ratio), and K-line concept. Laminoplasty and laminectomy with/without fusion are posterior decompressive techniques that can be performed when the cervical lordosis is preserved and the $\mathrm{K}-$ line is positive with occupancy ratio of $<60 \%$. In both the procedures, spinal cord shifts posteriorly to achieve decompression $[\mathbf{1 9 , 2 0}]$. In laminoplasty, the spinal canal is expanded posteriorly, the laminae are preserved along with neck motion, but patient may develop postsurgical kyphosis and postsurgical progression of OPLL and in laminectomy with fusion and instrumentation, this surgical procedure prevents postsurgical kyphosis and postsurgical progression of OPLL [21]. However, the range of neck motion is lost after fusion surgery. There are two types of expansive laminoplasty - bilateral hinge type (French door/double door laminoplasty) and the unilateral hinge type (single door/open door laminoplasty). In this current study all patients underwent unilateral hinge type expansive laminoplasty and the average recovery rate of the mJOA score was about $64.65 \%$ and results after surgery according to the recovery rate $28.6 \%, 67.9 \%$, and $3.6 \%$ was good, fair and poor respectively (Table 3). A meta-analysis has reported an overall recovery rate of 43 to $63 \%$ following laminoplasty for OPLL [22]. Most of the patients shows rapid improvement within a year and continued improvement upto 10 years following the surgery. However, progression of OPLL resulted in development of late neurological deterioration in $15 \%-30 \%$ patients following surgery $[\mathbf{2 3}, \mathbf{2 4}, \mathbf{2 5}, \mathbf{2 6}]$. The high risk of progression of OPLL was seen in patients younger than 50 years with the continuous or mixed types $[\mathbf{2 7 , 2 8}]$. Additional reasons of late neurological deterioration were trauma and spinal cord atrophy [29]. In contrast, ossified LF and OPLL in the thoracic spine, has become common reasons of neurological deterioration [30]. Several factors that influence the surgical outcomes included older age $(>60$ years old) [23], longer duration of preoperative symptoms (> 1 year) [31], traumatic onset [32], OPLL occupancy ratio of $>60 \%$, kyphotic cervical alignment, myelomalacic changes in MRI [33,34], and severe myelopathy; [23] which are poor preoperative prognostic factors.

Table 3: Result after surgery according to recovery rate ${ }^{13,14}$

\begin{tabular}{|c|c|c|}
\hline & Frequency & Percentage (\%) \\
\hline Excellent $(\geq \mathbf{9 0 \%})$ & 0 & 28.6 \\
\hline Good (75 - 89\%) & 8 & 67.9 \\
\hline Fair (50 - 74\%) & 19 & 3.6 \\
\hline Poor $(\leq \mathbf{4 9 \%})$ & 1 & 0 \\
\hline
\end{tabular}


In our study 4 patients developed late deterioration of cervical myelopathy (decrease JOA score $>2$ points). In two of the them, late deterioration occurred 3 years after operation, these two patients had a long duration of preoperative symptoms (more than 2 years), severely compromised spinal canal along with myelomalacic changes in MRI and subsequent follow up MRI showed severe spinal cord atrophy, even though there was adequate expansion of the spinal canal. In other two patients, the progression of ossification was attributed for late neurological deterioration; and also, the both patients were diabetic \& under 50 years of age. Axial neck pain and neurological dysfunction has been reported after laminoplasty, which may be accounted due to development of sagittal malalignment following surgery $[35,36,37]$. LCL following laminoplasty contributes to kyphotic angulation, this does not allow the posterior shift of spinal cord, i.e., indirect decompression which results in residual anterior compression. Different literature has stated that there was a 6 - $9 \%$ chance of development of kyphosis following laminoplasty ${ }^{24}$ which were almost consistent with our report. Sakai et al. reported that following anterior decompression with fusion $(\mathrm{ACF})$, there was adequate preservation of the cervical sagittal alignment and balance; whereas following laminoplasty sagittal alignment and balance was deteriorated [38].

LCL following laminoplasty has been associated with several factors. The preoperative alignment of cervical lordotic curvature directly affects the postoperative alignment. Suk et al. ${ }^{39}$ reported that the preoperative lordotic angle of $<10^{0}$ may lead to cervical kyphosis postoperatively, while Choi et al. also stated that the preoperative lordosis of $8.5^{\circ}$ as predictive value for development of postoperative cervical kyphosis [40]. The posterior muscular-ligament complex disruption, particularly the detachment of insertions of C2 extensors; has also been linked in LCL $[38,41,42,43]$. A recent systematic review has reported the prevalence of C5 palsy following laminoplasty was $4.5 \%$ [44]. The rate of C5 palsy was $7.1 \%$ in this current study which was similar with the former studies $[\mathbf{4 4 , 4 5}]$. The precise causes remain unknown; however, surgical trauma, the tethering effect of the nerve root, an impingement of the stretched nerve root, and reperfusion injury of the spinal cord are thought to be the contributing factors for C5 paralysis $[\mathbf{4 6 , 4 7 ]}$. Spontaneous regression of these complication occurs within 1-2 years with usually good prognosis. Though expansive open door laminoplasty has resulted in improved neurological outcomes, some patients develop axial neck pain and/or stiffness around the neck and shoulder [48-51]. These complaints were also observed in our study $(10.7 \%)$ following the surgery. However, it is still not clear whether the axial pain is associated with laminoplasty or is merely a continuous preoperative spondylotic pain, or whether it represents de novo pain postoperatively. Some authors have found relatively higher rates of postoperative new onset neck pain, ${ }^{48}$ whereas others suggest that persistent pain is more common [52]. The possible factors of the axial pain have been described in several papers. Some researchers believe that the axial pains are caused due to damage to the neck muscles and facet joints $[48,49]$ and safeguarding of the $\mathrm{C} 2$ and $\mathrm{C} 7$ muscle attachments diminishes postoperative axial pain [53]. In the properly selected patient, outcomes are comparable, and in some studies superior, to other operations for OPLL.

\section{Conclusions:}

Expansive laminoplasty is a safe and effective non-fusion, decompressive procedure for management of cervical myelopathy with multilevel stenosis due to continuous and mixed type of OPLL, which preserved sagittal alignment, motion; and minimal to no axial neck pain.

Acknowledgements: None

Conflict of Interest: None

\section{References:}

1. Mineiro J, Lanca N. (2017) The neck. In: Blom A, Warwick D, Whitehouse MR, editors. Apley and Solomon's System of Orthopaedics and Trauma. 10 th ed. Boca Raton: CRC Press, Taylor and Francis Group 2017, 456-488.

2. Epstein N. (2002) Diagnosis and surgical management of ossification the posterior longitudinal ligament. Spine J. 2(6): 436-449.

3. Harsh GR 4th, Sypert GW, Weinstein PR, Ross DA, Wilson CB. (1987) Cervical spine stenosis secondary to ossification of the posterior longitudinal ligament. J Neurosurg. 67(3): 349-357. 
4. Tsuyama N. (1984) Ossification of the posterior longitudinal ligament of the spine. Clin Orthop Relat Res. 184: 71-84.

5. Fujimori T, Le H, Hu SS, Chin C, Pekmezci M, et al. (2015) Ossification of the posterior longitudinal ligament of the cervical spine in 3161 patients: a CT-based study. Spine (Phila Pa 1976). 40(7): E394-403.

6. Matsunaga S, Sakou T. (2006) Overview of epidemiology and genetics. In: Yonenobu K, Nakamura K, Toyama Y, editors. OPLL-Ossification of the Posterior Longitudinal Ligament. Tokyo: Springer. p. 7-9.

7. Ren Y, Liu ZZ, Feng J, Wan H, Li JH, et al. (2012) Association of a BMP9 haplotype with ossification of the posterior longitudinal ligament (OPLL) in a Chinese population. PLoS One.7(7): e40587.

8. Tanaka T, Ikari K, Furushima K, Okada A, Tanaka H, et al. (2003) Genome wide linkage and linkage disequilibrium analyses identify COL6A1, on chromosome 21 , as the locus for ossification of the posterior longitudinal ligament of the spine. Am J Hum Genet. 73(4): 812-22.

9. Tanaka M, Kanazawa A, Yonenobu K. Diagnosis of OPLL and OYL: overview. In: Yoneobu K, Nakamura K, Toyama Y, eds. OPLL: Ossification of the Posterior Longitudinal Ligament. 2nd ed. Tokyo, Japan: Springer. 2006:111-114.

10. Gok B, McLoughlin GS, Sciubba DM, McGirt MJ, Chaichana KL, et al. (2009) Surgical management of cervical spondylotic myelopathy with laminectomy and instrumented fusion. Neurol Res. 31: 1097-1101.

11. Matz PG, Anderson PA, Groff MW, et al. (2009) Cervical laminoplasty for the treatment of cervical degenerative myelopathy. Neurosurg Spine. 11(2): 157-169.

12. Bapat MR, Chaudhary K, Sharma A, Laheri V. (2008) Surgical approach to cervical spondylotic myelopathy on the basis of radiological patterns of compression: prospective analysis of 129 cases. Eur Spine J. 17(12):1651-1663.

13. Hirabayashi K, Miyakawa J, Satomi K, Maruyama T, Wakano K. (1981) Operative results and postoperative progression of ossification among patients with ossification of cervical posterior longitudinal ligament. Spine (Phila $\mathrm{Pa}$ 1976) 6:354-364.

14. Fu TS, Lai PL, Tsai TT, Niu CC, Chen LH, et al. (2005) Long term results of disc excision for recurrent lumbar disc herniation with or without posterolateral fusion. Spine (Phila Pa1976); 30: 2830-2834.

15. Kim B, Yoon DH, Ha Y, Yi S, Shin DA, et al. (2016) Relationship between T1 slope and loss of lordosis after laminoplasty in patients with cervical ossification of the posterior longitudinal ligament. Spine J. 16(2): 219-225.

16. Hirabayashi K, Watanabe K, Wakano K, Suzuki N, Satomi K, et al. (1983) Expansive open-door laminoplasty for cervical spinal stenotic myelopathy. Spine (Phila Pa 1976). 8(7):693-699.

17. Hirabayashi K and Satomi K. (1988) Operative procedure and results of expansive open-door laminoplasty. Spine. 13(7): 870-876.

18. Kawaguchi Y. (2019) Ossification of the posterior longitudinal ligament: Etiology, prevalence, progression, and surgical strategies. Indian Spine J. 2: 52-8.

19. Hirabayashi K, Toyama Y, Chiba K. (1999) Expansive laminoplasty for myelopathy in ossification of the longitudinal ligament. Clin Orthop Relat Res. 359: 35-48.

20. Aita I, Hayashi K, Wadano Y, Yabuki T. (1998) Posterior movement and enlargement of the spinal cord after cervical laminoplasty. J Bone Joint Surg Br. 80: 33-7.

21. Koda M, Mochizuki M, Konishi H, Aiba A, Kadota R, et al. (2016) Comparison of clinical outcomes between laminoplasty, posterior decompression with instrumented fusion, and anterior decompression with fusion for K-line (-) cervical ossification of the posterior longitudinal ligament. Eur Spine J. 25(7): 2294-2301.

22. An HS, Al-Shihabi L, Kurd M. (2014) Surgical treatment for ossification of the posterior longitudinal ligament in the cervical spine. J Am Acad Orthop Surg. 22(7): 420-429.

23. Iwasaki M, Kawaguchi Y, Kimura T, Yonenobu K. (2002) Long-term results of expansive laminoplasty for ossification of the posterior longitudinal ligament of the cervical spine: More than 10 years follow up. J Neurosurg. 96: 180-189.

24. Kawaguchi $\mathrm{Y}$, Kanamori M, Ishihara H, Ohmori K, Nakamura H, et al. (2003) Minimum 10-year follow-up after en bloc cervical laminoplasty. Clin Orthop Relat Res. 411: 129-139.

25. Ogawa Y, Toyama Y, Chiba K, Matsumoto M, et al. (2004) Long-term results of expansive open-door 
laminoplasty for ossification of the posterior longitudinal ligament of the cervical spine. J Neurosurg Spine. 1(2): 168-74.

26. Kawaguchi Y, Nakano M, Yasuda T, Seki S, Hori T, et al. (2016) More than 20 years follow-up after en bloc cervical laminoplasty. Spine (Phila Pa 1976) 41(20): 1570-1579.

27. Hori T, Kawaguchi Y, Kimura T. (2006) How does the ossification area of the posterior longitudinal ligament progress after cervical laminoplasty? Spine (Phila Pa 1976) 31(24): 2807-2812.

28. Chen G, Wang Y, Wang Z, Zhu R, Yang H, et al. (2018) Analysis of C5 palsy in cervical myelopathy with massive anterior compression following laminoplasty. J Orthop Surg Res. 13(1): 26.

29. Seichi A, Iwasaki M, Nakamura K. (2003) Double-door laminoplasty by splitting spinous process. In: Nakamura K, Toyama Y, Hoshino Y, editors. Cervical Laminoplasty. Tokyo: Springer. p. 47-62.

30. Kawaguchi Y, Kanamori M, Ishihara H, Nakamura H, Sugimori K, et al. (2001) Progression of ossification of the posterior longitudinal ligament following en bloc cervical laminoplasty. J Bone Joint Surg Am. 83A: 1798-1802

31. Satomi K, Ogawa J, Ishii Y, Hirabayashi K. (2001) Short-term complications and long-term results of expansive open-door laminoplasty for cervical stenotic myelopathy. Spine J. 1(1): 26-30.

32. Fujimura Y, Nakamura M, Toyama Y. (1998) Influence of minor trauma on surgical results in patients with cervical OPLL. J Spinal Disord. 11: 16-20.

33. Yukawa Y, Kato F, Yoshihara H, Yanase M, Ito K. (2007) MR T2 image classification in cervical compression myelopathy: Predictor of surgical outcomes. Spine (Phila Pa 1976); 32: 1675-1678.

34. Wada E, Yonenobu K, Suzuki S, Kanazawa A, Ochi T. (1999) Can intramedullary signal change on magnetic resonance imaging predict surgical outcome in cervical spondylotic myelopathy? Spine (Phila Pa 1976) 24: 455-461. 35. Suda K, Abumi K, Ito M, Shono Y, Kaneda K, et al. (2003) Local kyphosis reduces surgical outcomes of expansive open-door laminoplasty for cervical spondylotic myelopathy. Spine (Phila Pa 1976). 28(12): 1258-1262.
36. Zhang JT, Li JQ, Niu RJ, Liu Z, Tong T, et al. (2017) Predictors of cervical lordosis loss after laminoplasty in patients with cervical spondylotic myelopathy. Eur Spine J. 26(4): 1205-1210.

37. Sakai K, Yoshii T, Hirai T, Arai Y, Torigoe I, et al. (2016) Cervical Sagittal Imbalance is a Predictor of Kyphotic Deformity After Laminoplasty in Cervical Spondylotic Myelopathy Patients Without Preoperative Kyphotic Alignment. Spine (Phila Pa 1976). 41(4): 299-305.

38. Sakai K, Yoshii T, Hirai T, Arai Y, Shinomiya K, et al. (2017) Impact of the surgical treatment for degenerative cervical myelopathy on the preoperative cervical sagittal balance: a review of prospective comparative cohort between anterior decompression with fusion and laminoplasty. Eur Spine J. 26(1): 104-112.

39. Suk KS, Kim KT, Lee JH, et al. (2007) Sagittal alignment of the cervical spine after the laminoplasty. Spine. 32(23): E656-660.

40. Choi I, Roh SW, Rhim SC, et al. (2018) The time course of cervical alignment after cervical expansive laminoplasty: determining optimal cut-off preoperative angle for predicting postoperative kyphosis. Medicine (Baltimore). 97(47): e13335.

41.Kurokawa R and Kim P. (2015) Cervical laminoplasty: the history and the future. Neurol Med Chir (Tokyo). 55(7): 529539.

42. Lin S, Zhou F, Sun Y, et al. (2015) The severity of operative invasion to the posterior muscular-ligament complex influences cervical sagittal balance after open-door laminoplasty. Eur Spine J. 24(1): 127-135.

43. Iizuka H, Nakajima T, Iizuka Y, et al. (2007) Cervical malalignment after laminoplasty: relationship to deep extensor musculature of the cervical spine and neurological outcome. J Neurosurg Spine. 7(6): 610-614.

44. Shou F, Li Z, Wang H, Yan C, Liu Q, et al. Prevalence of C5 nerve root palsy after cervical decompressive surgery: a meta-analysis. Eur Spine J. 2015; 24: 2724-2734.

45. Gu Y, Cao P, Gao R, Tian Y, Liang L, et al. (2014) Incidence and risk factors of C5 palsy following posterior cervical decompression: a systematic review. PLoS One. 9: e101933 
46. Tsuzuki N, Hirabayashi S, Saiki K, Ishizuka K. (2003)

Paralysis of the arm occurring after decompression of the cervical spinal cord. In: Nakamura K, Toyama Y, Hoshino Y, editors. Cervical Laminoplasty. Tokyo: Springer. p. 153-62.

47. Chiba K, Maruiwa H, Matsumoto M, Toyama Y. (2003) Segmental motor paralysis after laminoplasty. In: Nakamura K, Toyama Y, Hoshino Y, editors. Cervical laminoplasty. Tokyo: Springer. p. 163-167.

48. Hosono N, Yonenobu K, Ono K. (1996) Neck and shoulder pain after laminoplasty. A noticeable complication. Spine (Phila Pa 1976). 21:1969-1973.

49. Kawaguchi Y, Matsui H, Ishihara H, Gejo R, Yoshino O. (1999) Axial symptoms after en bloc cervical laminoplasty. J Spinal Disord. 12: 392-395.

50. Saita K, Hoshino Y. (2003) Cervical pain after cervical laminoplasty: Causes and treatment. In: Nakamura K,
Toyama Y, Hoshino Y, editors. Cervical Laminoplasty. Tokyo: Springer. p. 169-174.

51. Nahara Y, Kiya T. (2003) Neck and shoulder pain: Postoperative neck pain with special reference to postoperative immobilization. In: Nakamura K, Toyama Y, Hoshino Y, editors. Cervical Laminoplasty. Tokyo: Springer. p. $175-81$.

52. Yoshida M, Tamaki T, Kawakami M, Nakatani N, Ando M, et al. (2002) Does reconstruction of posterior ligamentous complex with extensor musculature decrease axial symptoms after cervical laminoplasty? Spine (Phila Pa 1976). 27(13): 1414-1418.

53. Kato M, Nakamura H, Konishi S, Dohzono S, Toyoda H, et al. (2008) Effect of preserving paraspinal muscles on postoperative axial pain in the selective cervical laminoplasty. Spine (Phila Pa 1976). 33(14): E455-459. 